\title{
Trinuclear Gold(I) Triazolates: A New Class of Wide-Band
} Phosphors and Sensors

Chi Yang, ${ }^{\S}$ Marc Messerschmidt, ${ }^{\mathrm{r}}$ Philip Coppens, ${ }^{*, \mathrm{Y}}$ and Mohammad A. Omary ${ }^{\star, \S}$ Department of Chemistry, University of North Texas, Denton, Texas 76203, and Department of Chemistry, University at Buffalo, State University of New York, Buffalo, New York 14260-3000

E-mail: omary@unt.edu; coppens@buffalo.edu

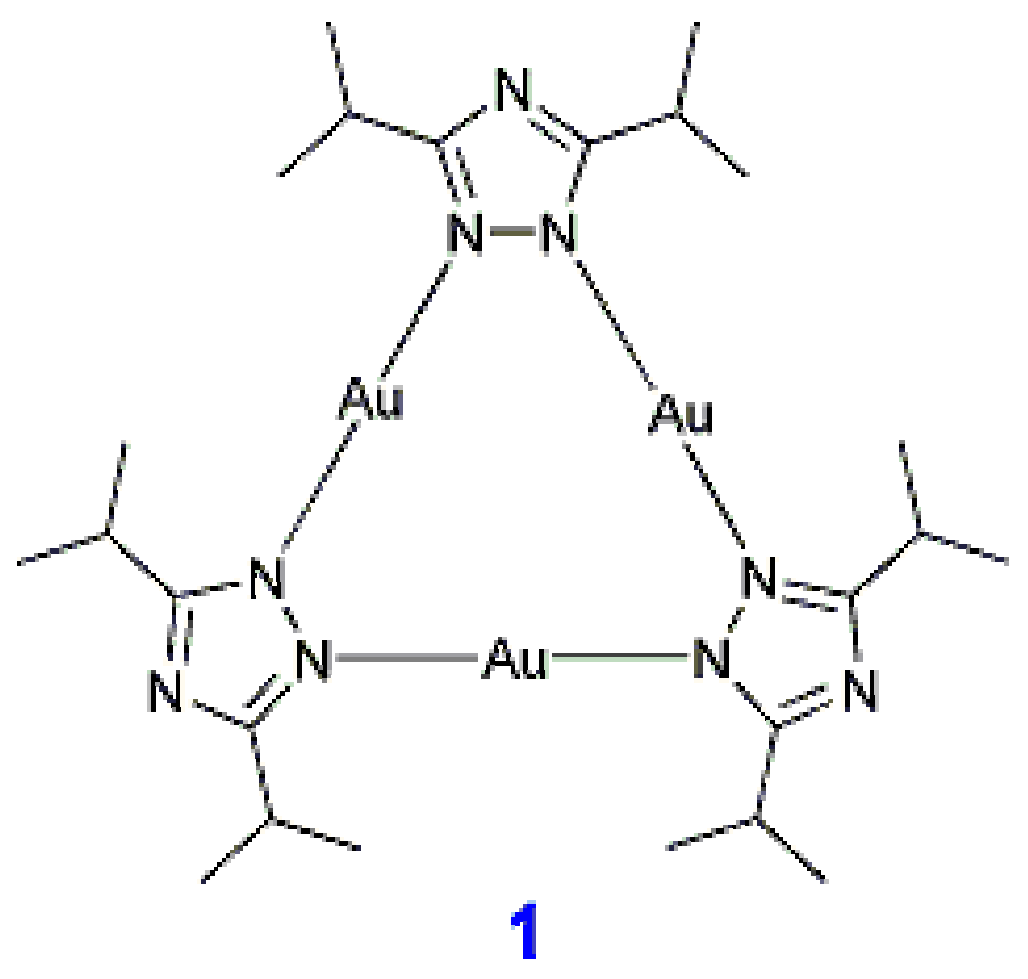




\section{SECTION S1. EXPERIMENTAL PROCEDURES}

General Synthetic Procedures. All manipulations were carried out under argon atmosphere using standard Schlenk techniques. Solvents were purchased from commercial sources, distilled from conventional drying agents and degassed by the freeze-pump-thaw method twice prior to use. Glassware was oven-dried at $150{ }^{\circ} \mathrm{C}$ overnight.

Physical Measurements. The luminescence measurements were carried out at the University of North Texas for crystalline material. Steady-state luminescence spectra were acquired with a PTI QuantaMaster Model QM-4 scanning spectrofluorometer. The excitation and emission spectra were corrected for the wavelength-dependent lamp intensity and detector response, respectively. Lifetime and time-resolved data were acquired using fluorescence and phosphorescence sub-system add-ons to the PTI instrument. The pulsed excitation source was generated using the $337.1 \mathrm{~nm}$ line of the $\mathrm{N}_{2}$ laser pumping a freshly-prepared $1 \times 10^{-2} \mathrm{M}$ solution of the continuum laser dye Coumarin-540A in ethanol, the output of which was appropriately tuned and frequency doubled to attain the excitation wavelengths needed based on the luminescence excitation spectra. Cooling in temperature-dependent measurements for the crystals was achieved using an Oxford optical cryostat, model Optistat CF ST, interfaced with a liquid helium tank.

The infrared measurements were carried out in a Midac Corporation Model 101025 IR spectrometer. The samples were prepared as $\mathrm{KBr}$ pellets. ${ }^{1} \mathrm{H}$ NMR spectra were recorded on a Varian Gemini-200 Fourier-transform spectrometer operating at $200 \mathrm{MHz}$. Chemical shifts were recorded relative to TMS.

Elemental analysis was obtained commercially from QTI for a recrystallized solid sample of $\mathbf{1}$.

X-ray Crystallographic Details and Structure Solution. X-ray diffraction data were collected at 95(2)K using a Bruker SMART APEX2 CCD diffractometer installed at a rotating anode source (MoK $\alpha$ radiation, $\lambda=0.71073 \AA$ ), and equipped with an Oxford Cryosystems nitrogen gas-flow apparatus. The 
data were collected by the rotation method with $0.3^{\circ}$ frame-width ( $\omega$ scan) and 10 sec exposure time per frame. Three sets of data (600 frames in each set) were collected, nominally covering complete reciprocal space. For comparison purposes one set (600 frames) was collected at room temperature. The data were integrated, scaled, sorted and averaged using the APEXII software package. ${ }^{1}$ The structure was solved by Direct methods using SHELXS. ${ }^{1}$ The structure was refined by full-matrix least squares on $F^{2}$. Hydrogen atoms were inserted at calculated positions and constrained with isotropic thermal parameters.

1. Bruker-AXS, Madison. Wisc, 2005.

\section{SECTION S2. FURTHER EXPERIMENTAL DATA}

Elemental Analysis. Anal. Calcd for $\mathrm{C}_{24} \mathrm{H}_{42} \mathrm{~N}_{9} \mathrm{Au}_{3}$ : C, 27.52; H, 4.04; N, 12.03. Found: C, 27.51; H, $3.96 ; \mathrm{N}, 11.93$.

\section{NMR Data for 1:}

${ }^{1} \mathrm{H} \mathrm{NMR}\left(\mathrm{CDCl}_{3}, 200.1 \mathrm{MHz}\right.$, room temp): $\delta=3.12\left[\right.$ sept $\left., J=6.8 \mathrm{~Hz}, 1 \mathrm{H}, \mathrm{CH}\left(\mathrm{CH}_{3}\right)_{2}\right], 1.21[d, J=$ $\left.6.8 \mathrm{~Hz}, 6 \mathrm{H}, \mathrm{CH}\left(\mathrm{CH}_{3}\right)_{2}\right]$.

Infrared Data. IR spectra are provided in Figures S1 and S2 for 1 and the free ligand, respectively. 
Figure S1. IR spectrum of $\mathbf{1}$.

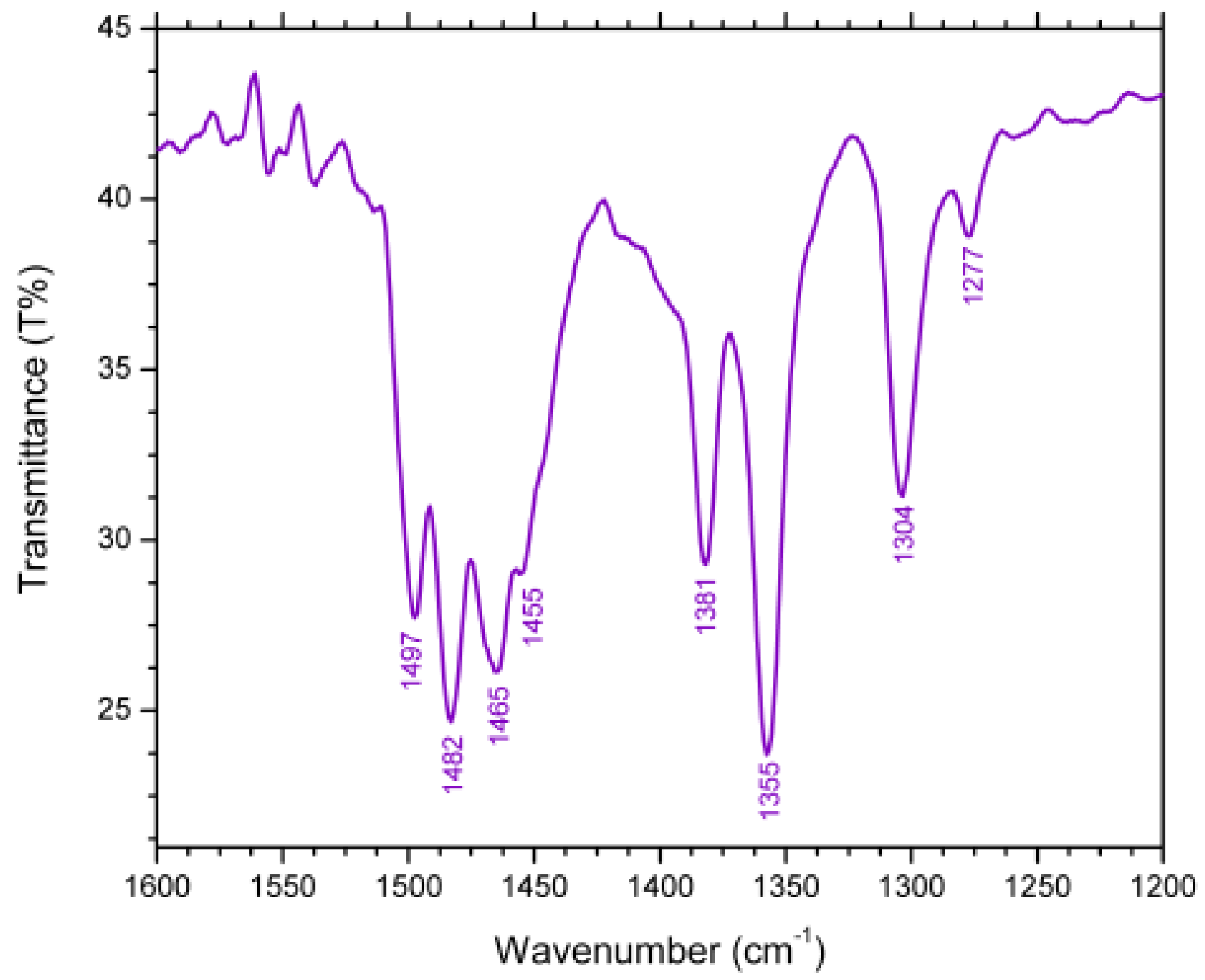


Figure S2. IR spectrum of the free ligand.

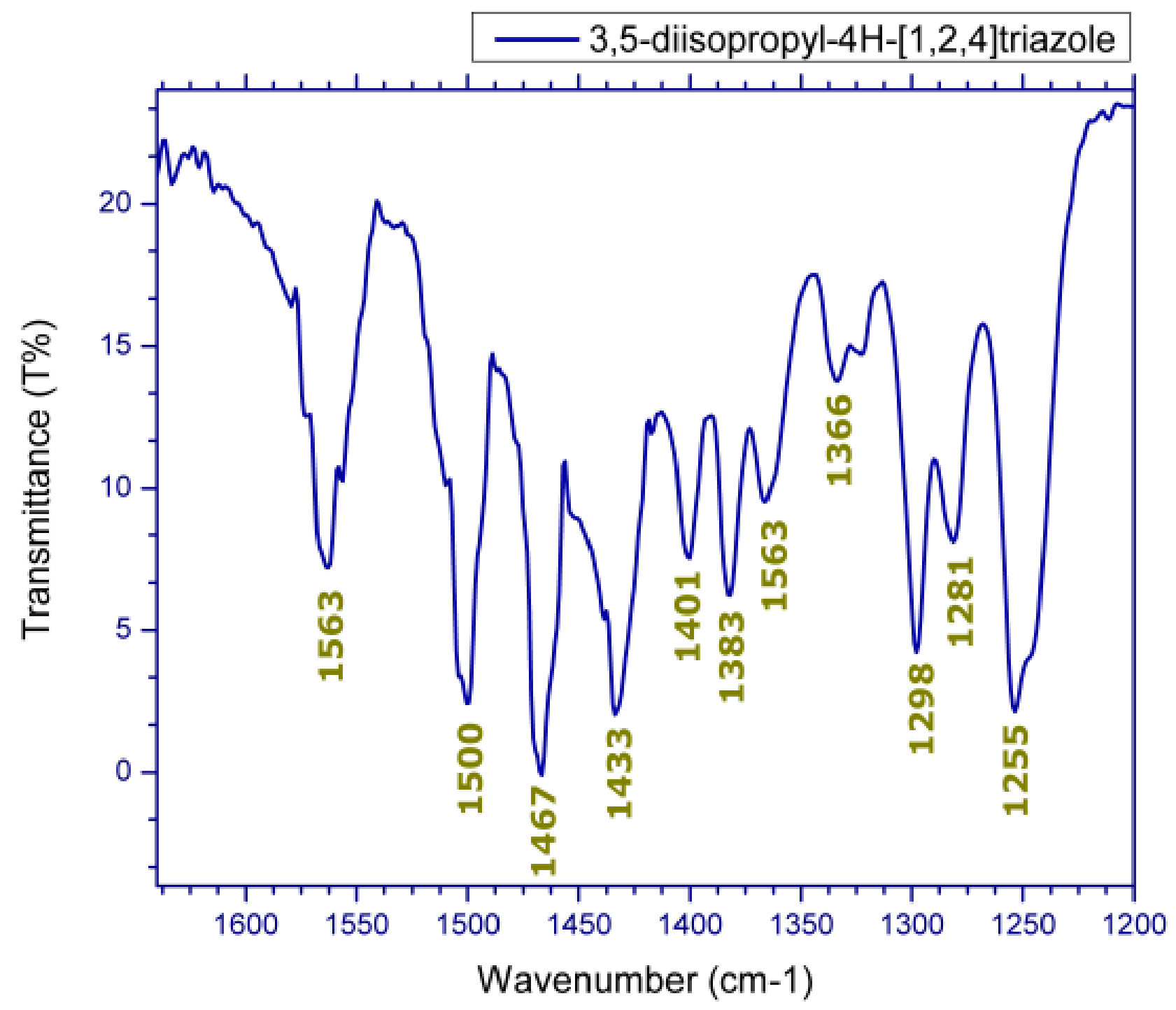


Table S1. Cell dimensions for 1 .

\begin{tabular}{|c|c|c|c|c|c|c|c|}
\hline T & A & b & c & $\alpha$ & $\beta$ & $\gamma$ & $Z$ \\
\hline $95 \mathrm{~K}$ & 25.2847 & 13.8608 & 17.1400 & 90.000 & 98.361 & 90.000 & 8 \\
\hline RT & 25.0368 & 14.0465 & 18.0574 & 90.000 & 97.191 & 90.000 & 8 \\
\hline
\end{tabular}

Table S2. Selected Bond Distances $(\AA)$ and Angles $\left({ }^{\circ}\right)$ for $\mathbf{1}$.

\begin{tabular}{|c|c|c|}
\hline & $95 \mathrm{~K}$ & RT \\
\hline \multicolumn{3}{|l|}{ Bond distances[̊] } \\
\hline $\mathrm{Au}(1)-\mathrm{Au}(2)$ & 3.39 & 3.36 \\
\hline $\mathrm{Au}(2)-\mathrm{Au}(3)$ & 3.40 & 3.38 \\
\hline $\mathrm{Au}(3)-\mathrm{Au}(1)$ & 3.36 & 3.40 \\
\hline $\mathrm{Au}(1)-\mathrm{Au}(1)^{\prime}$ & 3.19 & 3.46 \\
\hline $\mathrm{Au}(2)-\mathrm{Au}(3)^{\prime}$ & 3.55 & 3.42 \\
\hline \multicolumn{3}{|l|}{ Distances from Au plane } \\
\hline $\mathrm{Au}(1)^{\prime}$ & 3.18 & 3.35 \\
\hline $\mathrm{Au}(2)^{\prime}$ & 3.33 & 3.34 \\
\hline $\mathrm{Au}(3)^{\prime}$ & 3.37 & 3.33 \\
\hline \multicolumn{3}{|l|}{ Angles $\left[{ }^{\circ}\right]$} \\
\hline & & \\
\hline angle & -23.34 & -22.30 \\
\hline Angle between gold planes ${ }^{a}$ & 3.30 & 0.30 \\
\hline
\end{tabular}

a: "Gold planes" are defined by Au1, Au2, Au3 and the symmetry related atoms in the dimer of trimers. 